\title{
O VIÉS COGNITIVO DOS INVESTIDORES NO MERCADO FINANCEIRO \\ BRASILEIRO: UM ESTUDO NO SETOR BANCÁRIO NO PERÍODO DE 2015
}

A 2019.

\author{
Aline Bueno Araujo (buenoaraujoa @ gmail.com) \\ UVA-Universidade Veiga de Almeida \\ Daiane Rodrigues dos Santos (daianesantoseco@gmail.com) \\ UVA-Universidade Veiga de Almeida \\ Fernando Medina (fernando.medina@uva.br) \\ UVA-Universidade Veiga de Almeida \\ Izabel Cristina Corrêa Saldanha Matsuzaki (izabel.saldanha@uva.br) \\ UVA-Universidade Veiga de Almeida \\ Soraida Aguilar Vargas (soraguilar@gmail.com) \\ PUC Rio - Pontifícia Universidade Católica do Rio
}

\section{RESUMO}

O efeito manada é cada vez mais comum na compra e venda de ativos de muitas empresas pertencentes ao Ibovespa e o estudo para compreender a sua existência tem sido cada vez mais frequente em finanças. O presente artigo visa identificar a sua existência salientando o conceito de Finanças Comportamentais. Utilizou-se o histórico de ativos de três dos cinco melhores bancos do país no período de 2015 a 2019 para identificar a ocorrência do efeito manada. Para a identificação empregamos o método conhecido como CSSD - Cross Sectional Standart Deviation, o qual através da hipótese "O comportamento não racional no sentido econômico de um grupo de investidores pode influenciar na precificação dos ativos?", foi capaz de identificar a existência do comportamento manada em dois dos três bancos. O resultado mostrou-se satisfatório corroborando com o referencial teórico no qual destaca o efeito manada como uma possível causa das variações excessivas de preço dos ativos.

Palavras-Chave: Bancos; Efeito Manada; Finanças Comportamentais; Heurística. 


\section{Introdução}

Finanças Comportamentais surge para contrapor os argumentos ditados pela Teoria Moderna de Fianças, a qual de acordo com Silva et. al. (2009), tem por premissa a perfeita racionalidade do investidor de forma a crer que este seja capaz de absorver todas as informações disponíveis do mercado, para que dessa forma, as suas tomadas de decisões refletissem nos preços do mercado tornando-o um mercado eficiente.

Em 1974 Tversky e Kahneman abordam em seu estudo Judgment under Uncertainty: Heuristics and Biases algumas heurísticas (atalhos mentais) capazes de influenciar os investidores na tomada de decisão. Muito estudadas pela psicologia cognitiva, as heurísticas criadas por Tversky e Kahneman (1974) são representatividade, ancoragem e ajuste e disponibilidade, e abordam muito o conceito de como são realizadas mentalmente as tomadas de decisões dos investidores e seus julgamentos.

Dentro desses aspectos cognitivos existe a heurística conhecida como efeito manada ou comportamento manada, que ocorre quando "um grupo de investidores imita o comportamento de outro, ignorando suas próprias análises e percepções do mercado" (SANCHES, 2013 apud NETO et. al., 2016, p. 607). O presente estudo tenta identificar o efeito manada nos retornos dos ativos de três grandes bancos brasileiros, para tal empregamos o método conhecido como CSSD - Cross Sectional Standart Deviation.

\subsection{Finanças Comportamentais}

Para Arruda (2006) apud Silva e Lucena (2018) Finanças Comportamentais contribui de forma diferente para o mercado financeiro, pois, o estudo visa explorar o comportamento do agente financeiro quando o mesmo reage aos erros que são considerados na Moderna Teoria de Finanças.

Melo e Fucidji (2016) em seu estudo, abordam sobre a racionalidade limitada criado pelo autor Herbert Alexander Simon, em que Simon expressa o limite racional como dependente da dinâmica do sistema econômico, destacando que as opiniões e conhecimento dos investidores variam conforme o passar do tempo, assim como o próprio âmbito econômico. No entanto, Simon (1955) apud Yoshinaga e Ramalho (2014), em crítica com a Moderna Teoria o autor afirma que há limites na racionalidade do indivíduo, assim de acordo com as autoras, houve uma abertura para o conceito de Finanças Comportamentais. 
Para Calado (2013) Finanças Comportamentais advém economia, possuindo o mesmo exórdio filosófico. No entanto, ainda acentuando o conceito do autor, este viés faz uso de aspectos associados a psicologia na definição do comportamento dos agentes financeiros. Ariely (2008) acredita que a Economia Comportamental é um campo que aborda conjuntamente a economia e a psicologia. $\mathrm{O}$ autor ainda salienta que o indivíduo, independentemente de seu cargo, age de maneira previsível e não racional e que obter a compreensão desta não racionalidade é sinônimo de melhoria em sua tomada de decisão.

\subsection{Efeito Manada}

"Os estudos na área de finanças comportamentais versam sobre os erros de cognição nos modelos racionais e tradicionais de finanças corporativas" (NETO E FREIRE 2013, p. 25). Tendo em vista esses erros cognitivos, o presente estudo terá foco na análise do efeito manada conhecido como comportamento manada ou herding behavior (comportamento rebanho), dentro do mercado de ativos.

"Em um contexto de precificação de ativos, a crença que o
comportamento do rebanho reflete a resposta irracional é
particularmente preocupante porque implica que os preços podem ser
afastados de seus valores de equilíbrio. Sob essa premissa, os
investidores são expostos aos caprichos imprevisíveis dos rebanhos e
podem ser forçados a negociar a preços ineficientes". (CHRISTIE E HUANG, 1995, p.:31)

Silva, Barbedo e Araújo (2015) salientam que o efeito manada é um dos principais problemas abordados pela Finanças Comportamentais e que por meio deste, acredita-se que os preços no mercado de ações tendem a se movimentarem de forma aleatória. "O comportamento manada ocorre em função dos ruídos e opiniões dos indivíduos quanto à situação financeira da empresa, principalmente quando a informação é de um especialista ou formador de opinião" (NETO E FREIRE 2013, p.: 27). "Sob essa premissa, os investidores são expostos aos caprichos imprevisíveis dos rebanhos e podem ser forçados a negociar a preços ineficientes" (CHRISTIE E HUANG 1995, p.:31). 


\section{Estudo Comportamental do Efeito Manada}

Para se obter uma análise sobre o comportamento manada no histórico das empresas, o presente artigo irá utilizar a metodologia chamada de Desvio Padrão Transversal dos Retornos, também conhecida como CSSD (Cross-Sectional Standart Deviation).

Desta forma, o Desvio Padrão Transversal do Retornos se dá pela fórmula:

$$
\left.\operatorname{CSSD}_{t}=\sqrt{\frac{1}{N-1} \sum_{i=1}^{n}\left(R_{i, t}-R_{m, t}\right.}\right)^{2}
$$

Onde:

- $\quad \boldsymbol{R}_{\boldsymbol{i}, \boldsymbol{t}}=$ Retorno do ativo $i$ no período $t$;

- $\boldsymbol{R}_{\boldsymbol{m}, \boldsymbol{t}}=$ Retorno médio transversal da carteira de mercado

- $\quad \boldsymbol{N}=$ Número de ativos analisados.

Christie e Huang (1995) afirmam que a ocorrência do efeito manada se dá pela turbulência no mercado de ações e para a averiguação do fenômeno dentro deste ambiente compreende-se que:

$$
\operatorname{CSSD}_{t}=\alpha+\beta_{1} D_{t}^{L}+\beta_{1} D_{t}^{U}+\varepsilon_{t}
$$

Onde:

$\boldsymbol{D}_{t}^{L}=1$, se os retornos do mercado estiverem na extremidade inferior da distribuição $D_{t}^{L}=0$, caso contrário; e

$\boldsymbol{D}_{\boldsymbol{t}}^{\boldsymbol{U}}=1$, se os retornos do mercado estiverem na extremidade superior da distribuição

$\mathrm{e}$

$D_{t}^{U}=0$, caso contrário.

"O coeficiente $\alpha$ a denota a dispersão média da amostra, excluindo as regiões cobertas pelas duas variáveis dummy $\boldsymbol{D}_{\boldsymbol{t}}^{L}$ e $\boldsymbol{D}_{\boldsymbol{t}}^{U}$. Modelos racionais de precificação de ativos preveem coeficientes significativamente positivos para $\beta 1$ e $\beta 2$, e estimativas negativas de $\beta 1$ e $\beta 2$ seriam consistentes com a presença do comportamento do manada”. (CRISTIE E HUANG 1995, p. 33)

Na equação 2 é feita uma regressão linear, na qual utiliza-se duas variáveis nas quais se o retorno médio na extremidade superior ou inferior ela valerá um evidenciando a existência do efeito manda. Caso contrário, valerá zero não ultrapassando do limite estipulado destacando a não ocorrência do efeito. 
Silva, Barbedo e Araujo (2015) acreditam que, para que haja eficiência na pesquisa, o estudo se dá em analisar as extremidades do gráfico (superior e inferior) utilizando percentis de retorno de $1 \%, 5 \%$ e $10 \%$ para os coeficientes inferiores e os $99 \%$, $95 \%$ e 90\% para os superiores para cada ativo representante de cada banco e coeficientes dummies que demonstram as mudanças comportamentais dos investidores e desta forma pode-se encontrar o efeito manada.

\section{Análises De Resultados e discussão}

O presente artigo foca seu estudo sobre o efeito manada dentro do banco de ativos de três dos principais bancos do país: Bradesco, Itaú e Santander. A análise se baseia na verificação diária dos retornos dos ativos com os dados fornecidos pela Bolsa Balcão $[\mathrm{B}]^{3}$. O período avaliado para a obtenção dos coeficientes de regressão foi de $01 \mathrm{de}$ janeiro de 2015 a 23 de agosto de 2019.

Dentro do seguimento de Christie e Huang (1995) quando as variáveis $\beta 1$ e/ou $\beta 2$ são positivas, considera-se que houve uma dispersão em relação aos preços dos ativos, o que caracterizaria a não formação do comportamento manada. Outra observação feita pelos autores, é a não formação de dispersão, que ocorre quando os $\beta 1$ e/ou $\beta 2$ são negativos, essa inexistência de dispersão significa que houve o acumulo de ações iguais na mesma direção, ocasionando uma variação significativa dos retornos causando a ultrapassagem dos limites de 1 e -1 das variáveis e caracterizando-se em um efeito manada.

\subsection{Banco Bradesco}

As tabelas 1 e 2 fazem as análises descritivas das regressões dos ativos BBDC4 e BBDC3 respectivamente com base na equação 2. Com base nos estudos feitos pelos autores não houve a ocorrência do efeito manada em ambos os ativos, tendo em vista que ambos os betas ( $\beta 1$ e $\beta 2$ ) obtiveram um resultado positivo. Além disso, o resultado apresenta a não ultrapassagem das do limite entre 1 e -1 o que significa que, dentro do período de 5 anos, a variação entre os preços dos ativos do banco Bradesco não sofreu, consideravelmente, afluxo de ações dentro de uma mesma direção no que diz a respeito da variação de preços dos ativos. 
Portanto, houve uma uniformidade nas variações nos preços dos ativos do banco Bradesco, as quais, não ocasionaram uma queda ou um aumento significativo dos preços.

Tabela 1: Coeficientes de Regressão BBDC4 para o período de Market stress.

\begin{tabular}{l|l|l|c|l|l|c}
\hline $\begin{array}{l}\text { Coeficentes } \\
\text { Estimados }(\alpha)\end{array}$ & Coeficientes & Valor Estimado & $\begin{array}{c}p \text {-valor } \\
\text { Associado ao } \\
\text { Beta }\end{array}$ & Coeficientes & Valor Estimado & $\begin{array}{c}p \text {-valor } \\
\text { Associado ao } \\
\text { Beta }\end{array}$ \\
\hline 0,00038 & $\beta_{1}(10 \%)$ & 0,00061 & $(0,00786)$ & $\beta_{2}(90 \%)$ & 0,00556 & $(0,00103)$ \\
\hline 0,00054 & $\beta_{1}(05 \%)$ & 0,00134 & $(0,00657)$ & $\beta_{2}(95 \%)$ & 0,00762 & $(0,00134)$ \\
\hline 0,00089 & $\beta_{1}(01 \%)$ & 0,00027 & $(0,00096)$ & $\beta_{2}(99 \%)$ & 0,01361 & $(0,00292)$ \\
\hline
\end{tabular}

Fonte: Autores com base nos dados fornecidos pela $[\mathrm{B}]^{3}$

Tabela 2: Coeficientes de Regressão BBDC3 para o período de Market stress.

\begin{tabular}{l|l|l|c|l|l|l}
\hline $\begin{array}{l}\text { Coeficentes } \\
\text { Estimados }(\alpha)\end{array}$ & Coeficientes & Valor Estimado & $\begin{array}{c}\text { p-valor Associado ao } \\
\text { Beta }\end{array}$ & Coeficientes & Valor Estimado & $\begin{array}{c}\text { p-valor Associado } \\
\text { ao Beta }\end{array}$ \\
\hline 0,00029 & $\beta_{1}(10 \%)$ & 0,00115 & $(0,00503)$ & $\beta_{2}(90 \%)$ & 0,0048 & $(0,0225)$ \\
\hline 0,00043 & $\beta_{1}(05 \%)$ & 0,00256 & $(0,00383)$ & $\beta_{2}(95 \%)$ & 0,00653 & $(0,0277)$ \\
\hline 0,00075 & $\beta_{1}(01 \%)$ & 0,00323 & $(0,00034)$ & $\beta_{2}(99 \%)$ & 0,00672 & $(0,0015)$ \\
\hline
\end{tabular}

Fonte: Autores com base nos dados fornecidos pela $[\mathrm{B}]^{3}$

\subsection{Banco Itaú}

Ao contrário do que ocorre com as ações do banco Bradesco, nos resultados obtidos para as ações do banco Itaú, podemos detectar a presença do herding behavior. No seu ativo cuja sigla representativa é ITUB3 na tabela 4, avaliou-se a presença do efeito manada nas duas variáveis, beta $\beta 1$ e $\beta 2$ no percentil $1 \%$ (variável inferior e superior, respectivamente), e $\beta 1$ no percentil de $10 \%$. A afirmativa se dá pelo fato destas variáveis obtiverem resultados negativos, expondo assim a ultrapassagem do limite de 1 e -1 conforme estipulado pelos autores desta metodologia.

Contradizendo o resultado encontrado para a ação ITUB3, a ação ITUB4 na tabela 3, dentro do período analisado, não apresentou significativamente algum resultado que comprovasse o comportamento manada, pois, tanto seus coeficientes, quanto suas variáveis obtiveram resultados positivos.

Entende-se então que para o banco Itaú houve um crescimento nos preços dos ativos nos que diz respeito ao percentil superior de $99 \%$ e uma queda de considerável nos 
percentis de $1 \%$ e $10 \%$ no ativo ITUB3 na tabela 4 e poucas variações nos preços dos ativos no ITUB4 na tabela 3.

Tabela 3: Coeficientes de Regressão ITUB4 para o período de Market Stress.

\begin{tabular}{l|l|l|c|l|l|c}
\hline $\begin{array}{l}\text { Coeficentes } \\
\text { Estimados }(\alpha)\end{array}$ & Coeficientes & Valor Estimado & $\begin{array}{c}\text { p-valor Associado a0 } \\
\text { Beta }\end{array}$ & Coeficientes & Valor Estimado & $\begin{array}{c}\text { p-valor Associado } \\
\text { ao Beta }\end{array}$ \\
\hline 0,00055 & $\beta_{1}(10 \%)$ & 0,00001 & $(0,00003)$ & $\beta_{2}(90 \%)$ & 0,0001 & $(0,00000)$ \\
\hline 0,00056 & $\beta_{1}(05 \%)$ & 0,00004 & $(0,00256)$ & $\beta_{2}(95 \%)$ & 0,00009 & $(0,00870)$ \\
\hline 0,00056 & $\beta_{1}(01 \%)$ & 0,00011 & $(0,00000)$ & $\beta_{2}(99 \%)$ & 0,00005 & $(0,00001)$ \\
\hline
\end{tabular}

Fonte: Autores com base nos dados fornecidos pela $[\mathrm{B}]^{3}$

Tabela 4: Coeficientes de Regressão ITUB3 para o período de Market Stress.

\begin{tabular}{l|l|l|c|l|l|c}
\hline $\begin{array}{l}\text { Coeficentes } \\
\text { Estimados }(\alpha)\end{array}$ & Coeficientes & Valor Estimado & $\begin{array}{c}p \text {-valor Associado ao } \\
\text { Beta }\end{array}$ & Coeficientes & Valor Estimado & $\begin{array}{c}p \text {-valor Associado } \\
\text { ao Beta }\end{array}$ \\
\hline 0,00035 & $\beta_{1}(10 \%)$ & $-0,00035$ & $(0,021619)$ & $\beta_{2}(90 \%)$ & 0,0082 & $(0,00000)$ \\
\hline 0,0005 & $\beta_{1}(05 \%)$ & 0,00052 & $(0,02780)$ & $\beta_{2}(95 \%)$ & 0,01153 & $(0,00720)$ \\
\hline 0,00103 & $\beta_{1}(01 \%)$ & $-0,00116$ & $(0,00453)$ & $\beta_{2}(99 \%)$ & $-0,02174$ & $(0,00000)$ \\
\hline
\end{tabular}

Fonte: Autores com base nos dados fornecidos pela $[\mathrm{B}]^{3}$

\subsection{Banco Santander}

$\mathrm{Na}$ análise das ações do banco Santander, em todas as tabelas 5, 6 e 7 fica evidente que o mesmo sofreu a ocorrência do efeito manada, tendo em vista o resultado negativo em cada um dos percentis inferiores, com exceção do SANB4 1\% para a variável $\beta 1$. No ativo SANB3, os percentis inferiores de $1 \%, 5 \%$ e $10 \%$ resultou em $\beta 1$ negativo evidenciando a queda dos preços das ações deste ativo.

$\mathrm{Na}$ tabela 6 que representa o ativo SANB4, os indícios do efeito manada surgiram no percentil superior de $95 \%$ o que resulta em um crescimento abrupto do ativo e nos percentis inferiores de $5 \%$ e $10 \%$, resultando na queda abrupta dos preços do mesmo. No ativo SANB11 houve um aumento de preço no que diz a respeito ao resultado do percentil superior de $99 \%$ e uma queda em todos os percentis inferiores. Portanto, compreende-se que houve variações significativas nos preços dos ativos com maior ocorrência nas quedas do que nos aumentos de preços destes. 
Tabela 5: Coeficientes de Regressão SANB3 para o período de Market stress.

\begin{tabular}{l|l|l|c|l|l|c}
\hline $\begin{array}{l}\text { Coeficentes } \\
\text { Estimados }(\alpha)\end{array}$ & Coeficientes & Valor Estimado & $\begin{array}{c}p \text {-valor Associado ao } \\
\text { Beta }\end{array}$ & Coeficientes & Valor Estimado & $\begin{array}{c}\text { p-valor Associado } \\
\text { ao Beta }\end{array}$ \\
\hline 0,00123 & $\beta_{1}(10 \%)$ & $-0,00135$ & $(0,00061)$ & $\beta_{2}(90 \%)$ & 0,03734 & $(0,00000)$ \\
\hline 0,00199 & $\beta_{1}(05 \%)$ & $-0,00441$ & $(0,04750)$ & $\beta_{2}(95 \%)$ & 0,00554 & $(0,04092)$ \\
\hline 0,0017 & $\beta_{1}(01 \%)$ & $-0,0021$ & $(0,00000)$ & $\beta_{2}(99 \%)$ & 0,0703 & $(0,00000)$ \\
\hline
\end{tabular}

Fonte: Autores com base nos dados fornecidos pela $[\mathrm{B}]^{3}$

Tabela 6: Coeficientes de Regressão SANB4 para o período de Market stress.

\begin{tabular}{l|l|l|c|l|l|c}
\hline $\begin{array}{l}\text { Coeficentes } \\
\text { Estimados }(\alpha)\end{array}$ & Coeficientes & Valor Estimado & $\begin{array}{c}p \text {-valor Associado ao } \\
\text { Beta }\end{array}$ & Coeficientes & Valor Estimado & $\begin{array}{c}p \text {-valor Associado } \\
\text { ao Beta }\end{array}$ \\
\hline 0,00171 & $\beta_{1}(10 \%)$ & $-0,00058$ & $(0,00000)$ & $\beta_{2}(90 \%)$ & 0,00672 & $(0,00000)$ \\
\hline 0,00217 & $\beta_{1}(05 \%)$ & $-0,00417$ & $(0,00001)$ & $\beta_{2}(95 \%)$ & $-0,01884$ & $(0,00000)$ \\
\hline 0,00174 & $\beta_{1}(01 \%)$ & 0,00045 & $(0,00202)$ & $\beta_{2}(99 \%)$ & 0,01124 & $(0,00000)$ \\
\hline
\end{tabular}

Fonte: Autores com base nos dados fornecidos pela $[\mathrm{B}]^{3}$

Tabela 7: Coeficientes de Regressão SANB11 para o período de Market stress.

\begin{tabular}{l|l|l|c|l|l|l}
\hline $\begin{array}{l}\text { Coeficentes } \\
\text { Estimados }(\alpha)\end{array}$ & Coeficientes & Valor Estimado & $\begin{array}{c}p \text {-valor Associado a0 } \\
\text { Beta }\end{array}$ & Coeficientes & Valor Estimado & $\begin{array}{c}\text { p-valor Associado } \\
\text { ao Beta }\end{array}$ \\
\hline 0,00153 & $\beta_{1}(10 \%)$ & $-0,00259$ & $(0,015382)$ & $\beta_{2}(90 \%)$ & 0,00794 & $(0,01905)$ \\
\hline 0,00127 & $\beta_{1}(05 \%)$ & $-0,00014$ & $(0,015069)$ & $\beta_{2}(95 \%)$ & 0,00821 & $(0,00000)$ \\
\hline 0,00166 & $\beta_{1}(01 \%)$ & $-0,00476$ & $(0,016001)$ & $\beta_{2}(99 \%)$ & $-0,00034$ & $(0,00000)$ \\
\hline
\end{tabular}

Fonte: Autores com base nos dados fornecidos pela $[\mathrm{B}]^{3}$

Essas variações nos preços dos ativos corroboram com o estudo de Finanças Comportamentais afirmando a influência do investidor no mercado de ativos quando as tomadas de decisões são de cunho não racional.

Interpretando todo o estudo teórico e analítico aqui presente, compreende-se que dentro do período analisado, neste mercado específico de ações, ocorreu a insuficiência das informações no que diz respeito às empresas para com os investidores, e por consequência resultou em um aumento abrupto das vendas dos ativos como mostra $\beta 1$. Da mesma forma ocorre com o $\beta 2$, porém de maneira inversa e neste caso, como há o aumento dos preços dos ativos, entende-se que houve disponibilidade e absorção das informações necessárias para o mercado se manter eficiente salientando a Teoria Moderna de Finanças. Tendo em vista esta análise, compreende-se que é de suma importância a disponibilidade das informações sobre os bancos para se manterem em um equilíbrio na bolsa de valores e para que os mesmos não sofram da ocorrência do comportamento manada por parte dos investidores. 


\section{Conclusão}

Este trabalho teve por objetivo contribuir para a literatura já existente sobre o efeito manada de forma a destacar a existência deste efeito dentro do mercado de ações brasileiro. O presente estudo verificou que dentro do período de 2015 a 2019, dois dos três bancos estudados, Santander e Itaú, foram os que mais sofreram a ocorrência do efeito manada. Nosso resultado corrobora com os de Neto e Freire (2013), no qual os autores salientam que os modelos racionais e tradicionais de finanças corporativas não levam em consideração os possíveis erros de cognição quanto ao efeito manada.

Em partes, o resultado do nosso estudo para o setor bancário brasileiro, no que tange alguns dos principais bancos privados atuantes no país, foi de encontro a Teoria Clássica de Finanças salientada pelos autores Ferreira et. al. (2008). A teoria em questão garante que os mercados são eficazes e os preços representam todas as informações disponíveis. Porém, quando se aborda sobre o comportamento manada em relação a precificação dos ativos como os autores Christie e Huang (1995), entende-se que nem todos os investidores possuem total conhecimento ou a obtenção de todas as informações, pois crê-se que de acordo com Barreto, Murcia e Lima (2012) umas das causas deste efeito se encontra na disponibilidade de informações sobre uma determinada empresa.

Em vista os argumentos apresentados neste presente artigo, entende-se que os atalhos cognitivos tomados pelos investidores, são capazes de influenciar nas variações de precificação do mercado, podendo esta variação ter um resultado disperso dentro das análises, o que significa que os investidores tomaram suas decisões de forma totalmente racional, validando os argumentos da Teoria Clássica de Finanças, ou seja, não ocasionando o efeito manada sinônimo da irracionalidade do investidor ou estas mesmas variáveis obtendo um resultado negativo, validando a ocorrência do efeito manada com a sua análise tendo um forte agrupamento de ações de investidores dentro de uma mesma linha de raciocínio normalmente ocasionada pela não racionalidade destes agentes. 


\section{REFERÊNCIAS}

[B]3- Brasil Bolsa Balcão: "Pesquisa de bancos: Banco Bradesco.” 2019

Disponível em: <http://www.b3.com.br/pt_br/busca/?query=bradesco> Acesso: 21/11/2019

[B] 3. Brasil Bolsa Balcão: "Pesquisa de bancos: Banco Santander." 2019

Disponível em: <http://www.b3.com.br/pt_br/busca/?query=Santander> Acesso: 21/11/2019

[B] 3 - Brasil Bolsa Balcão: "Pesquisa de bancos: Banco Itaú Unibanco.” 2019

Disponível em: <http://www.b3.com.br/pt_br/busca/?query=itauunibanco> Acesso: 21/11/2019

ARILEY, D. Predictably Irrational: The hidden Forces That Shape Our Decisions. New York: Harper Collins ed. 2008.

BARRETO, E., MURCIA, F., LIMA, I. Impacto da mensuração a valor justo na crise financeira mundial: Identificando a percepção de especialistas em economia e mercado financeiro. Revista de Contabilidade e Organizações, vol. $6 \mathrm{n}^{\circ} 15,44-59$, set., 2012.

CALADO, L.R. Finanças tradicionais x Finanças Comportamentais. $1^{\text {a }}$ Edição, Rupave International 2013.

CHRISTIE, W., HUANG, R. Do Individual Returns Herda round the Market? Financial Analysts Journal, vol. 51, nº4, 31-37, agosto, 1995.

FERREIRRA, Aurélio. Tomada de Decisão: os aspectos do processo decisório e o uso da racionalidade na busca pelo sucesso. Anais do IV Encontro de Ensino, Pesquisa e Extensão da Faculdade Senac PE. 1-5, 2010. Disponível em: < http://www.faculdadesenacpe.edu.br/encontro-de-ensinopesquisa/2011/IV/anais/comunicacao/008_2010_ap_oral.pdf > Acesso em: 10/08/2019

FERREIRA, J., MACEDO, J., LAGIOIA, U., LIBONATI, J., MACIEL, C, Aplicação das Finanças Comportamentais no Processo de Tomada de Decisão dos Investidores no Mercado de Capitais. II Seminário UFPE de Ciências Contábeis, p.1-17, set. 2008. Disponível em: < https://s3.amazonaws.com/academia.edu.documents/39244017/artigo_14.pdf?response-contentdisposition=inline \%3B\%20filename\%3DA_APLICACAO_DAS_FINANCAS_COMPORTAMENTAI S.pdf\&X-Amz-Algorithm=AWS4-HMAC-SHA256\&X-Amz-

redential=AKIAIWOWYYGZ2Y53UL3A\%2F20200305\%2Fus-east-1\%2Fs3\%2Faws4_request\&XAmz-Date=20200305T225046Z\&X-Amz-Expires=3600\&X-Amz-SignedHeaders=host\&X-Amz-

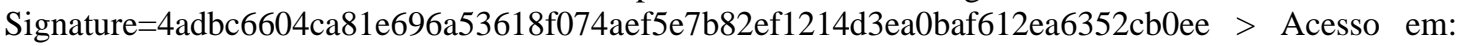
10/04/2019

LUCENA, E. R. F. C., Análise da Relação entre a Capacidade Cognitiva e a Ocorrência dos Vieses Cognitivos da Representatividade no Julgamento. Tese (Doutorado em Ciências Contábeis) apresentada ao Programa Multi-institucional e Inter-Regional de Pós- graduação - UnB/UFPB/UFRN, Natal p.14, 2015.

MELO, T. M., FUCIDJI, J. R. Racionalidade Limitada e a Tomada de Decisão. Revista de Economia Política, vol. 36, n³(144), 622-645, jul.-set.2016.

NETO, L. M., FREIRE, F. Comportamento Manada: Estudo Aplicado em Estudantes do Curso de Ciências Contábeis. RIC- Revista de Informação Contábil, vol. 7, nº1, 23-34, 2013.

NETO, L. M., SERRANO, A. L., NETO, J. C., FREITAS, R. L., ABREU, E. S. Efeito Manada no Mercado de Capitais: Um Estudo com Gerentes de Bancos Públicos do Distrito Federal. RACE- Revista de Administração, Contabilidade e Economia, vol.15, n²2, 601-620, 2016.

SILVA, J. X., BARBEDO, C. H., ARAÚJO, G. S. Há Efeito Manada em Ações com Alta Liquidez do Mercado Brasileiro? Banco Central do Brasil- Trabalhos para discussão. Brasília, no 386, 1-19, abril 2015.

SILVA, V. D., LUCENA, W. G. Finanças Comportamentais: Análise dos Fatores do Efeito Manada em Empresas Listadas na [B] $]^{3}$ - Brasil Bolsa Balcão. Revista Catarinense Contábil, vol.18, 1-20, 2019.

SILVA, R. F., LAGIOIA, U. C., MACIEL, C. V., RODRIGUES, R. N. Finanças Comportamentais: um estudo comparativo utilizando a teoria dos prospectos com os alunos e graduação do curso de ciências contábeis. RBGN- Revista Brasileira de Gestão e Negócios, vol. 11, n³3, 383-403, out/dez.2009.

TVERSKY, A., KANHEMAN, D. Judgment under Uncertainty: Heuristics and Biases. Science, vol. 185, nº 4157, 1124-1131, set. 1974.

YOSHINAGA, C. E., RAMALHO, T. B. Finanças Comportamentais no Brasil: uma aplicação da teoria da perspectiva em potenciais investidores. RBGN- Revista Brasileira de Gestão de Negócios, vol. 16, no53, 594-615, out./dez. 2014. 